\title{
VOZES DO LESTE: OS JORNALISMOS LITERÁRIOS DE SVETLANA ALEKIÉVITCH E HANNA KRALL
}

\author{
Mateus Yuri Passos* \\ Arthur Breccio Marchetto**
}

RESUMO

A partir de um close reading de trechos de três obras pretendemos compreender as especificidades do jornalismo literário produzido por mulheres eslavas, a partir do trabalho da bielorussa Svetlana Aleksiévitch e da polonesa Hanna Krall. Buscamos distinguir as particularidades de estilo e voz de cada autora, suas estratégias narrativo-discursivas.

Palavras-chave: Jornalismo literário; Jornalismo eslavo; Narrativa e experienciação; Svetlana Aleksiévich; Hanna Krall.

\section{VOZES DO LESTE}

A premiação da bielorussa Svetlana Aleksiévich com o Prêmio Nobel de Literatura em 2015 abriu as portas do mundo para uma mais ampla recepção e reconhecimento do jornalismo literário como campo de práticas literárias de alto valor artístico; por outro lado, no campo de estudos de jornalismo literário, no qual esse valor já era reconhecido, despertou-se um interesse não apenas pela produção de Aleksiévitch em particular, mas para outros jornalistas literários que escrevem em línguas eslavas (russo, ucraniano, polonês etc), dos quais apenas o polonês Ryszard Kapuściński (1952-2007) já ocupava certo lugar canônico no cenário global.

Nesse sentido, o impacto desse reconhecimento pode ser identificado em três dimensões principais: a primeira, como já sinalizado, é a valorização de algumas configurações do trabalho jornalístico como arte e como literatura,

* Professor do Programa de Pós-Graduação em Comunicação Social da Universidade Metodista de São Paulo (Umesp). Doutor em Teoria e História Literária pela Universidade Estadual de Campinas (Unicamp).E-mail: mateus.passos@gmail.com

** Mestrando em Comunicação Social da Universidade Metodista de São Paulo (Umesp) com bolsa Capes. Graduado em Jornalismo pela Universidade Metodista de São Paulo. E-mail: arthur.marchetto@gmail. com 
efetivamente; a segunda, o crescimento de um interesse editorial e acadêmico por jornalistas literários oriundos de países eslavos; a terceira, uma atenção de igual ordem pela produção de mulheres no jornalismo literário.

No Brasil, identificamos a valorização principal de Eliane Brum como jornalista literária cuja sensibilidade e capacidade empática a singularizam como repórter e narradora (LIMA; MARTINEZ, 2014). No entanto, considerando o campo de produção de jornalismo literário como um universo vasto configurado não apenas por um gênero ou forma singulares, mas por um conjunto amplo e diverso de gêneros discursivos ${ }^{1}$ bastante distintos entre si, situados em um ponto de intersecção entre o jornalismo e a literatura (PASSOS, 2016), compreendemos que aos eixos de modalidade textual e de gênero se acresce o do contexto cultural, a configuração dos sujeitos diretamente relacionada à sua experiência do lugar e do momento histórico em que se formam e atuam - o que, evidentemente, tem o gênero como uma de suas dimensões. Nos instiga, a partir dessa constatação, indentificar as diferentes configurações que o jornalismo literário poderia assumir ao ser produzido por mulheres de cultura eslava, que vivenciaram um processo histórico bastante singular ao crescerem na União Soviética.

Assim, buscamos compreender especificidades narrativas das obras de Aleksiévitch e da polonesa Hanna Krall - de projeção internacional menor, mas crescente, e bastante reconhecida em seu país. Pretendemos distinguir as particularidades de estilo e voz de cada autora, suas estratégias narrativo-discursivas e o modo como apresentam o ponto de vista não-oficial, o que compreendemos como um traço geral do jornalismo literário (PASSOS, 2016) - em contraponto à reprodução das ideologias ligadas a instituições de poder governamentais ou financeiras -, e em especial à forma de reconstruir a vivência de mulheres para que a leitura permita simular sua experienciação.

A partir dessa premissa analisamos a produção das autoras partir das obras Vozes de Tchernóbil e A Guerra Não Tem Rosto de Mulher, de Aleksiévitch, e The Woman from Hamburg and other true stories (não traduzida em português), de Krall. Procuramos compreender o trabalho das duas autoras como mobilizações de gêneros discursivos distintos, e, a partir de seleção

\footnotetext{
Compreendendo gêneros discursivos pelos termos de Bakhtin (2016), que os define como enunciados relativamente estáveis em termos de tema, composição e estilo. Essa noção bakhtiniana não pretende organizar/hierarquizar gêneros em um conjunto pequeno de nomenclaturas, pois os vê como um campo de infinitas possibilidades: variações em quaisquer desses três elementos essenciais configurariam novos gêneros, muitas vezes derivados de gêneros já estabelecidos ou "formas híbridas" que combinam características de um ou mais gêneros ou conjunto de gêneros.
} 
qualitativa, realizamos close readings de trechos dos livros escolhidos que nortearam as discussões apresentadas. Compreendemos o procedimento do close reading a partir de Richards (2017), cuja definição o delineia como leitura atenta às minúcias do texto, buscando identificar nos detalhes e no específico pistas para carcterizar estratégias textuais de forma mais ampla. É preciso, naturalmente, fazer ressalvas quanto a certa limitação das análises pelo fato de estarmos lidando com traduções e não com os textos originais - temos consciência de não lidar com as palavras ou construções exatas das repórtes, mas sim com escolhas realizadas pelos tradutores no esforço de reconstruir ou mesmo recriar os textos de Aleksiévitch e Krall em outros idiomas.

\section{HANNA KRALL: LACUNAS E SILÊNCIOS}

Nascida em Varsóvia em 1935, Hanna Krall é hoje a segunda repórter polonesa mais traduzida no mundo, ficando atrás apenas de Ryszard Kapuściński, e influenciando jornalistas de gerações mais jovens como Mariusz Szczygieł, autor de Gottland. Foi a única sobrevivente de uma família de judeus massacrada durante o Holocausto, tendo sido resgatada de um veículo que transportava moradores da cidade para o gueto onde os judeus foram durante muitos anos forçosamente confinados, e posteriormente abrigada e escondida entre a população polonesa "ariana" (CULTURE.PL, s/d). Ao contrário de outros escritores que viveram aquele momento de exceção, como Primo Levi, Krall não fez até o momento qualquer trabalho memorial ou de ficção em que lida diretamente com essa experiência da infância; porém, a reconhece como uma vivência única e valiosa que, se por um lado a teria tornado "décadas mais velha" do que pessoas que nasceram no mesmo local poucos anos depois e não vivenciaram a perseguição ao judeus, por outro lhe daria também maturidade precoce e uma capacidade ímpar de compreender seus personagens - boa parte deles também judeus (OGIOLD, 2001).

Iniciou sua carreira aos 20 anos no jornal diário Zycie Warszawy e em 1966 tornou-se correspondente na União Soviética para a revista Polytika parte do trabalho de reportagem que produziu durante a estada de quatro anos foi publicada em 1972 no livro Na wschód od Arbatu [A leste de Arbat]. Seu primeiro trabalho de grande impacto viria poucos anos depois, publicado em partes na revista Odra em 1976 e na forma de livro no ano seguinte - sob o título de Zdażyć przé Panem Bogiem [Ponha-se diante de Deus], a reportagem tinha como protagonista Marek Edelman, um dos líderes do Levante do 
Gueto de Varsóvia, um ato de resistência contra o transporte dos moradores para o campo de concentração de Treblinka.

Ao longo das décadas seguintes, Krall alternaria um trabalho como freelancer com empregos fixos em jornais e revistas, desenvolvendo um estilo narrativo que causaria espanto a Tom Wolfe (2005) pelo caráter distinto que apresenta em relação à abordagem estílistica que ficou mais fortemente vinculada ao Novo Jornalismo e ao jornalismo literário, na qual eventos testemunhados ou relatados eram reconstruídos em cenas minuciosas, com riqueza de descrições de modo a se caracterizar o estilo de vida dos sujeitos retratados. O estilo de Krall seguiria numa linha diversa, na qual a narração dos acontecimentos parece ser reduzida ao mínimo, ao essencial, com uma crueza de linguagem não muito diferente da prosa kafkiana, não raro com saltos cronológicos de meses ou anos, e com a passagem de informações essenciais do plano mais evidente do texto para uma lacuna a ser preenchida durante a leitura, pontas soltas a serem atadas por cada leitor (ISER, 1976), com um ou outro comentário pessoal. Ao adotar uma estratégia textual em que o autor não desaparece por trás da história e a deixa fluir "naturalmente", em vez disso a evidenciando como uma reconstrução - como artifício que causa estranhamento, como diria Chklovski (2013). Adotado mesmo em obras de ficção, esse procedimento teria, a seu ver, o papel de torná-las mais fiéis ao que considera a verdade dos fatos, pois interpretar, explicar e ordenar logicamente os acontecimentos tornaria o trabalho de reportagem inverídico:

My work as a reporter has taught me that logical stories, without riddles and holes in them, in which everything is obvious, tend to be untrue. And things that cannot be explained in any fashion really do happen. In the end, life on earth is also true, but it cannot be logically explained. (KRALL, 2005, loc.2040)

Essa é a abordagem utilizada dos textos de Taniec na cudzym weselu [Dançando no casamento de outra pessoa], coletânea de reportagens parcialmente reproduzida no livro The Woman from Hamburg and other true stories, tradução em língua inglesa que utilizamos como fonte e que reúne também alguns dos textos publicados em Dowody na istnienie [Provas de existência]; ambas as fontes trazem histórias sobre judeus que viveram o Holocausto ou o cotidiano judaico polonês anterior a 1939, com base em conversas - mais do que entrevistas - que Krall teve com diversos dos personagens e em pesquisa documental. 
A reportagem que dá título ao livro, "Ta z Hamburga" [A mulher de Hamburgo], traz um enredo inicial com alguns paralelos em relação à distopia The Handmaid's Tale, de Margaret Atwood. Na obra de ficção mulheres férteis são forçadas a agir como barrigas de aluguel para as esposas de militares que tomaram o poder - e dispensadas após darem à luz -; situação parcialmente análoga à de Regina, judia alemã acolhida em meio à perseguição nazista por Barbara e Jan, casal de poloneses que residia em Lviv, Ucrânia, e durante mais de um ano passa a viver boa parte das horas de cada dia dentro de um guarda-roupas, para que pudesse se ocultar de qualquer visita que pudesse denunciá-la. Regina engravida de Jan e Barbara, ameaçada pelo marido, acoberta o caso e passa a usar travesseiros por baixo da roupa, emulando sua própria gravidez. Quando Helusia nasce, Barbara a leva para apresentá-la aos vizinhos como sua própria filha. Dias depois, quando batiza a filha - a informação que contém o nome da arquidiocese é o único momento em que o texto precisa o local onde esse momento da história se ambienta -, o casal realiza uma festa para alguns convidados que dura até o amanhecer; Regina, que não há muito tempo acabara de dar à luz, passa o tempo todo no guarda-roupas. Meses depois, quando o exército soviético retoma a cidade, ela desaparece.

A partir daí, há diversos saltos cronológicos que demarcam o modo como se articula a relação entre as três mulheres - Barbara, Regina e a própria Helusia. O casal retorna à Polônia e Jan se demonstra obcecado, num primeiro momento, por encontrar Regina; em vez disso, é procurado por dois homens que a representavam e queriam recuperar a criança. Helusia passa a receber pacotes de Hamburgo com presentes. Barbara se refere a Regina, que os havia enviado, como madrinha de Helusia; se num primeiro momento os envios a incomodam profundamente, posteriormente passa mesmo a pedir à filha que pedisse alguns itens - como tecidos para seu vestido de primeira comunhão. Regina e Helusia passam a se corresponder - na verdade, Helusia escreve cartas, enquanto Regina envia apenas presentes e cheques, com uma ou outra fotografia ocasional - mas encontram-se pessoalmente apenas duas vezes. A primeira quando, aos 25 anos, Helusia descobre que Regina é sua mãe; a segunda 22 anos depois, quando Regina a convida para passar alguns dias em sua casa. Os dois encontros terminam com um surto angustiado de Regina, que em ambos os casos pede à filha que não venha mais vê-la, pois sua presença a faz reviver as aflições e o medo experienciados do passado.

A estratégia textual de Krall, como dissemos, envolve um distanciamento no tom e um trabalho em torno de lacunas de informação e de pistas para 
decifrá-las - mecanismo que, como aponta Wolfgang Iser (1976), promove um novo nível de interação entre texto e leitor, tornando o processo de leitura mais ativo. Por um lado, isso faz com que o texto seja articulado de uma forma bastante distinta daquilo a que convencionamos chamar de reportagem - as personagens não são indexadas no presente da forma costumeira, especialmente aquelas que mais provavelmente serviram de fonte a Krall; não sabemos com que trabalham, como vivem, sua existência de modo mais amplo: só interessa ao texto seus papéis no desenvolvimento dessa trama central.

Nesse sentido, chamam a atenção tanto os silenciamentos - um dos tipos de lacuna - quanto as pequenas pistas que podem nos levar a algumas conclusões. Uma dessas pistas surge quando Helusia confronta Regina pela primeira vez, e esta começa a repetir obsessivamente alguns conjuntos de frases, enquanto a filha desata a chorar. Algumas dessas frases - "It's true. I gave birth to you (...). I had to. I had to agree to everything. I wanted to live. I don't want to remember your father. I don't want to remember those times. I don't want to remember you, either." (KRALL, 2005, loc. 155) deixam subentendido que a relação entre Jan e Regina não era consensual.

Já os silenciamentos se colocam de forma mais marcada na ação das duas mães de Helusia e um dos primeiros exemplos podem ser vistos quando Barbara descobre o adultério de Jan:

One summer day, the wife came home from shopping. Her husband's jacket was hanging in the anteroom; he had come home from work a little earlier than usual. The door to the Jewess' room was locked. One autumn day her husband said, "Regina is pregnant" (KRALL, 2005, loc.92)

Krall não evidencia textualmente aquilo que parece óbvio ao leitor; em vez disso, o ocultamento da afirmação remete ao silêncio de Barbara sobre o assunto, mesmo antes de ser ameaçada pelo marido, algo que é espelhado pelo comportamento de Regina, que só falava quando lhe dirigiam a palavra, e remete à opressão a que ambas estavam submetidas, seja por medo da perseguição nazista, seja por medo do marido ou, de forma mais ampla, da opressão e julgamento de uma sociedade machista.

Em outro momento da reportagem, Helusia procura um escritório de advocacia para processar a mãe. A altercação entre ela e seu advogado é também sustentada a partir de lacunas dialógicas - apenas a fala o advogado é reproduzida, enquanto as reações de Helusia podem ser intuídas: 
First of all, we have to prove that she is your mother. Do you have witnesses? No? Well then, you see. The testimony of Mrs. Barbara S. should have been recorded. It should have been notarized. Now all that remains is a blood test. Are you determined to sue? So why did you come to a lawyer's office? (KRALL, 2005, loc.205).

A estratégia narrativa de Krall nos permite sentir e experienciar a opressão e o desespero - especialmente nas repetições obsessivas de frases por Regina - justamente por não dizer explicitamente que tal contexto era opressivo, que tal comportamento era desesperado: nossa interação com o texto por meio das lacunas e as conclusões que tiramos dele é que trazem o envolvimento com as situações e personagens.

Em outra reportagem reunida na mesma obra, "Dno oka" [The Back of the Eye], é possível evidenciar os saltos temporais e a presença de várias lacunas. No começo do texto somos ambientados numa vila sem nome que serve como ilustração em um cartão postal. A descrição de sua arquitetura e paisagem geográfica são os únicos elementos de identificação. A introdução de um dos personagens principais, Stanislaw W. (Stani), é feita sob a incerteza em um dos elementos desse cenário: "He worked in the sawmill. It may well be that it was he who sawed the boards from which the red-painted bench was constructed" (KRALL, 2005, loc.1114).

Além de Stani, nessa vila morava Gizela, uma mulher formada numa escola confessional de destaque, As Irmãs Franciscanas, que foi trabalhar para uma família da rica da região. Eles moravam em cima de um café, o mesmo café em que Stani se destacava por ser o melhor dançador de foxtrote da região. Os dois se conhecem e se casam.

Apesar de não sabermos onde estão, Krall nos conta algumas coisas. Stani não quis voltar para Polônia porque sua mãe tinha morrido e ele não gostava dos comunistas. Além disso, não queria continuar na Alemanha. A vontade deles era ir para a Austrália, mas sempre que faziam as malas, tinham que desfazer apressadamente porque Gizela estava grávida. Nunca se mudaram. No fim do parágrafo, Krall (2005, loc. 1134) sugere algo que não é evidenciado no momento: "Praise be to God. What would she have done in a foreign country with four children and without Stani”?

A narrativa dá um salto e apresenta dois diálogos semelhantes que acontecem em tempos diferente. O primeiro deles é entre Stani e Gizela; o outro entre Gizela e Stefan, o filho do casal. Ambas as conversas nascem 
do questionamento acerca da existência dos campos de concentração e complementam a narrativa de maneiras diferentes. Como resultado da primeira, Stani descreveu seu trabalho como refugiado nos campos de concentração e como ele ansiava por uma vida fácil, como ele gostaria de ser chamado pelos nazistas durante uma contagem que escolhia os que trabalhadores da vila. Depois, descobre-se que os destacados eram executados.

O outro diálogo apresenta o filho preso e indignado pelo conformismo do pai, que não quis se vingar e nem vingar a família. Antes que entendamos os motivos para a prisão do filho, somos levados para o futuro, em mais uma conversa entre mãe e filha. Tal diálogo gera uma afirmação enigmática que permanece sem explicação: "Mama, I think I finally understand him" (KRALL, 2005, loc. 1157).

Depois disso, Krall nos leva ao passado do pai. Contados pelos olhos do irmão mais novo, Krall descreve a casa, as minúcias da família e a reserva de Stani. Ninguém sabe as razões, a localização, os períodos ou os trajetos que Stani percorreu nos campos de concentração. As informações dele, como altura, peso e o fato de que passou por três campos, só são acessíveis por meios oficiais - parte delas por registros médicos. Logo entendemos o porquê do alívio pela permanência de Gizela na vila: Stani morreu aos 27 anos.

Krall passa a descrever as situações da mãe com os filhos e, principalmente, de injustiças com o filho. $\mathrm{Na}$ escola, ainda que fizessem as mesmas atividades que as outras crianças, os filhos eram os únicos que tomavam bronca da diretoria.

Gizela was upset. The other children told stories about their hero-fathers beautiful, noble stories. The fathers fired guns, primarily on the Eastern front. The fathers perished, but to the last drop of their blood... And what could her children tell them? That their father dreamed of being a number THREE or SIX? Could a father who ran barefoot around the barracks and prayed that one of those numbers... Could such a father be compared with heroes of Eastern front? (KRALL, 2005, loc. 1235).

Por não saber lidar com essa situação Gizela manda Stefan para um reformatório. Lá Stefan passa seis anos sob condições terríveis, severas. Além disso, Gizela tenta pedir apoio do governo, alegando que a doença de Stani foi ocasionada em decorrência do tempo que passou nos campos de trabalho. Achando as provas insuficientes, o benefício é negado à Gizela. 
Esse contexto, quando retornamos do salto, é o que serve para explicar a indignação do filho com o pai.

He addressed his father with growing indignation. As if there existed a connection between the director's fists and the stick his father didn't take, the bureaucrats dealing with compensation requests and the isolation call in the Maxium Security Section (KRALL, 2005, loc. 1288).

O crime de Stefan é descrito aos poucos. Primeiros descobrimos como foi se envolvendo em política até ingressa numa força no Red Army Faction (RAF). Como parte de um plano para liberar reféns do grupo das mãos do governo, a guerrilha sequestrou um empresário. Durante o sequestro, três policiais e um civil, o motorista, foram mortos. Além disso, a negociação foi um fracasso e gerou diversas mortes. Stefan conta que o plano deles não era aquele. Não sabiam da escolta. Acreditavam que os reféns seriam trocados. Ele foi condenado a prisão pérpetua.

\section{SVETLANA ALEKSIÉVITCH: MEMÓRIAS, SENTIMENTOS}

Svetlana Aleksievitch nasceu em 1948 no oeste da Ucrânia. Formada em jornalismo pela Universidade de Minsk, Svetlana começou sua carreira na editoria de cartas no jornal das fazendas coletivas, Сельская Газета [Jornal Rural]. Posteriormente trabalhou como repórter em outros jornais locais e como correspondente para a revista literária Неман [Neman]. Sua produção, conhecida principalmente nas terras eslavas, sempre foi voltada para as testemunhas de eventos dramáticos na ex-URSS e lhe rendeu prêmios como o Erich Maria Remarque Peace Prize, em 2001, o National Book Critics Circle Award, em 2006, e o Prémio Médicis Ensaio, em 2013, pelo O Fim do Homem Soviético. (CORREIO BRAZILIENSE, 2015).

Ao longo de sua carreira, Svetlana publicou seis livros: O mais recente е́ Время секона хэна [Tempo de segunda mão - publicado em português como Fim do homem soviético], de 2013, onde abordou a derrocada da União Soviética em diversas perspectivas, inclusive absorvendo o pequeno livro de 1993, Зачарованные смертью [Encantados com a morte], no qual discutiu o suicídio de jovens soviéticos; publicou Чернобыльскал молитва [Oração de Tchernóbil - publicado em português como Vozes de Tchernóbil em 1997, que recolhia depoimentos dos envolvidos no desastre na usina nuclear; em 1989 escreveu Цинковые мальчики [Rapazes de zinco] sobre a Guerra no 
Afeganistão de 1979 a 1989, com o título fazendo referência aos mortos que voltavam dos campos de batalha. Foi no ano de 1985 que lançou seus dois primeiros livros, Последние свидетели: сто недетских колыбельных [Últimas testemunhas: cem cantigas nada infantis], que tratava das crianças órfãs de guerra, е У войны не женское мицо [A guerra não tem rosto de mulher], seu livro de estreia, que tratava da perspectiva feminina da guerra.

Svetlana manteve a mesma estratégia de apuração e narrativa ao longo das suas publicações: colheu depoimentos, costurou todos eles numa colcha de retalhos e gerou uma narrativa polifônica sobre a vida interior e não-oficial de acontecimentos traumáticos para a vida soviética. Na introdução de $A$ Guerra não tem rosto de mulher, lemos trechos do diário de produção que revelam o pensamento por trás do processo criativo da jornalista e guiam a interpretação de seus livros.

A escritora afirma que, durante a infância, ouviu das mulheres de sua vila, principalmente de sua avó e de sua mãe, uma versão sobre a guerra muito diferente daquela contada pelos livros, uma abordagem canônica repleta de palavras "masculinas". Para ela,

a guerra "feminina" tem suas próprias cores, cheiros, sua iluminação e seu espaço sentimental. Suas próprias palavras. Nela, não há heróis nem façanhas incríveis, há apenas pessoas ocupadas com uma tarefa desumanamente humana. E ali sofrem apenas elas (as pessoas!), mas também a terra, os pássaros, as árvores. Todos os que vivem conosco na terra. Sofrem sem palavras, o que é ainda mais terrível (ALEKSIÉVITCH, 2016a, p.12).

Para organizar um formato adequado que desse vazão a essas vozes caladas, Svetlana investiu nos depoimentos e criou uma esfera intimista que violou os entraves que supervalorizavam a versão histórica neutra para chegar naquela versão repleta de minucias e, segundo a jornalista, daquilo que é humano.

Mais de uma vez me deparei com essas duas verdades convivendo em uma mesma pessoa: a verdade pessoal, relegada à clandestinidade, e a verdade geral, impregnada do espírito do tempo. Do cheiro dos jornais. A primeira raramente consegue ficar de pé diante da pressão da segunda (ALEKISÉVITCH, 2016a, p.133). 
Em seu trabalho, a memória adquiriu um importante papel enquanto recriação do passado e dos sentimentos. Mesmo atenta para os riscos de alteração, Svetlana afirma que a dor dos relatos aniquila a possibilidade de qualquer falseamento. Por isso passa a prestar atenção nas minucias, nos sentimentos, naquilo que parece pequeno e humano, ao invés dos grandes feitos e do heroísmo.

De um lado, o livro de Svetlana retratou as atrocidades da guerra, suas torturas e mutilações, a vida dos prisioneiros, o ódio, a morte, o estrupo; a guerra corpo a corpo que marcou a memória de diversas depoentes com os barulhos dos ossos quebrando e a brutalidade do conflito; as dificuldades do inverno, dos serviços realizados... No entanto, do outro lado, vemos as minucias, o amor, a vontade de usar vestidos e maquiagens, a inabilidade dos soldados em lidar com a menstruação, o vestido de noiva feitos de ataduras; o relato da mulher para quem ter que usar cuecas era a pior coisa da guerra; o contato com as flores, a terra e os animais. Todos esses fatores servem para estruturar o que Svetlana caracteriza como história dos sentimentos e da alma.

No terceiro capítulo do livro, intitulado "Fui a única a voltar para minha mãe", Svetlana vai ao encontro de Nina Iákovlevna Vichniévskaia, enfermeira-instrutora do Primeiro Batalhão da $32^{a}$ Brigada de Tanques do Quinto Exército. Nina participou de um dos maiores conflitos entre tanques, o embate de Prókhorovka, um enfrentamento de 1200 tanques de assalto entre o lado soviético e o alemão.

No seu trajeto, encontra dois homens que lutaram no front. A visão deles demonstra na prática o que Svetlana introduziu em seu diário; eles enaltecem a visão oficia da história e menosprezam as mulheres e seus relatos. Em primeiro lugar, ao falar da guerra, os homens defendem a guerra sob a perspectiva da pátria, da Grande Ideia e de Stalin.

Em seguida, um dos homens relata como recebeu duas mulheres em seu pelotão e as enxotou sob o argumento de que era trabalhoso e inútil adaptar o ambiente militar para elas e tê-las sob seu comando. Mesmo reconhecendo a importância das mulheres nos conflitos bélicos em toda a história da Rússia, os homens argumentam que se sentem culpados ao ver uma mulher dividindo o front com eles.

Entre as vozes não-nominadas, a que parece pertencer à Svetlana pergunta se elas não estavam salvando a pátria também, como qualquer soldado estava e um dos homens responde: "Isso mesmo, claro... Eu iria com uma mulher dessas numa missão de batedor, mas não me casaria com ela. Pois 
é... Estamos acostumados a pensar nas mulheres como mãe e noiva. A bela dama, enfim" e, no fim, afirma que "guerra é coisa de homem. O que foi, por acaso tem pouco homem sobre quem escrever no seu livro?" (ALEKSIÉVITCH, 2016a, p. 117).

Depois de comentários breves sobre a importância da mulher no front como mensageira e enfermeira, sobre Stalin e suas estratégias militares, eles culminam no assunto do amor na guerra. Ao perguntar se existia amor na guerra, Svetlana ouve dos homens que ele encontrou mulheres bonitas, mas não as enxergava como mulheres; durante a guerra elas eram irmãs. Mesmo assim, depois do fim do conflito, não conseguiam ficar com elas. Apesar da má fama que alguns tinham delas, o homem afirma que "elas eram, em sua maioria, mulheres direitas. Puras. Mas depois da guerra... Depois da sujeira, depois dos piolhos, depois das mortes... A gente queria algo bonito. Claro. Mulheres bonitas..." (ALEKSIÉVITCH, 2016a, p.119). Elas foram desprezadas pelos homens.

$\mathrm{Na}$ continuação desse capítulo, como contraposição ao diálogo, Svetlana apresenta uma mulher "masculinizada" que conta a sua visão de guerra com todas as minúcias. Antes de encontrar a subtenente Nina, Svetlana recebe a sugestão de confirmar quaisquer informações no Conselho de Veteranos. $\mathrm{Na}$ casa de Nina, a jornalista é recebida com um aperto de mão e nota que a decoração e os livros são todos relacionados ao cenário bélico; as bonecas usam fardas, o papel de parede tem tons militares, os chifres de um alce seguram um capacete de tanquista.

Depois do primeiro contato, Svetlana reflete sobre como é preciso se esforçar para acessar a memória pessoal e os sentimentos do indivíduo, especialmente nesses casos, onde a guerra deixou marcas tão profundas. Em seu relato, Nina prepara um texto que abandona, para falar da alma. Expõe como as meninas estavam eufóricas para entrar no exército, mas eram aceitas à contragosto.

O depoimento começa quando Nina relata a curiosidade e o choque que permeavam as novatas do esquadrão. Descreve como teve que se esforçar para ser aceita na unidade de tanques devido à sua estatura baixa, $1,60 \mathrm{~m}$, e na dificuldade que isso acarretaria para o cargo - quando um soldado é ferido "você tem que arrastá-lo para fora pela escotilha. Você consegue puxar um rapaz desses? Sabe como são fortes são os tanquistas? Quando você tem que entrar no tanque, está sob fogo inimigo. (...) Você sabe como é quando um tanque pega fogo?” (ALEKSIÉVITCH, 2016a, p.123). 
Nina Vichniévskaia apresenta também preocupações estéticas e práticas acerca dos penteados e dos uniformes militares feitos exclusivamente para as medidas masculinas, situações que se repetem ao longo do livro. Além disso, ela relata as dificuldades de se adaptar ao sistema militar. "Para nós, meninas, tudo no Exército era complicado. Achávamos muito difícil entender os sinais de distinção. Quando chegamos ainda existiam losanguinhos, cubinhos, tracinhos, e tinha que deduzir qual era a patente". No fim, "não gravávamos quem era tenente, quem era capitão, gravávamos outras coisas: se era bonito ou feio, ruivo ou alto" (ALEKSIÉVITCH, 2016a, p.127).

Nina também comenta sobre o a amor, quando descreve o relacionamento entre sua amiga e outro soldado, e sobre a descoberta da sexualidade, quando um tenente se insinua para ela antes de um ataque perigoso. De todas as suas amigas, descritas como mais aptas, Nina foi a única a voltar para sua mãe. Por fim, recita de maneira inesperada um poema que escreveu no front:

Uma moça ousada subiu na blindagem

Estava defendendo sua pátria.

Não se importava com balas, ou com estilhaços

Ardia o coração daquela moça.

Lembre-se, amigo, de sua beleza modesta,

Quando ela for carregada sobre um pedaco de lona... (ALEKSIÉVITCH, 2016a, p.131).

Por fim, conclui o relato refletindo sobre o porquê de ter ficado viva: "Por que fiquei viva? Para quê? Eu acho... Eu entendo que foi para contar isso..." (ALEKSIÉVITCH, 2016a, p.132). A pressão que a versão canonizada faz é forte. Assim como outras mulheres ao longo do livro, Nina escreveu para Svetlana pedindo que algumas passagens fossem suprimidas sob a preocupação de que sua imagem de heroína ruísse.

Em Vozes de Tchernóbil, Svetlana adota uma forma textual que a princípio parece derivar da que Kapuściński empregara em obras como Cesarz. [O Imperador], com o uso de longos depoimentos de seus entrevistados. No entanto, Kapuściński costura os depoimentos com outros longos trechos narrativos em que sua voz autoral se faz sentir; Aleksiévitch, com seu estilo mais consolidado e com uma produção menos suspeita, indexa sua presença em alguns poucos momentos em que os entrevistados de dirigem diretamente a ela e em um pequeno capítulo - "Entrevista da autora consigo mesma sobre a história omitida e sobre por que Tchernóbil desafia a nossa 
visão de mundo". Em seu escopo mais amplo, o livro é uma coletânea de monólogos de testemunhas não da explosão do quarto reator da usina nuclear de Tchernóbil, próxima à fronteira da Ucrânia com a Bielorússia, mas da disrupção de vidas causada pela explosão e pela contaminação nuclear - são monólogos de agricultores, médicos, aldeões, parteiras, engenheiros, liquidadores, jornalistas, professores de pequenas vilas, pais e mães, esposas e maridos, pessoas deslocadas de seus lares à força ou que continuaram a residir em zonas contaminadas. Num escopo mais amplo, está em jogo no livro a voz da ideologia do cotidiano (BAKHTIN, 2012), da voz e dos valores populares que escapam e por vezes se chocam com as instituições de poder adminstrativo, coercitivo e científico; mesmo os especialistas ouvidos cumprem ali menos o papel de analistas do que o de testemunhas, de sujeitos ativos em meio ao caos.

O livro se abre com "Uma solitária voz humana", monólogo de Liudmila Ignátineko, esposa de um dos bombeiros chamados para apagar o incêndio na usina e selar o reator, de modo a evitar que os danos se agravassem ainda mais. A narrativa é pontuada o tempo todo por omissões do poder público e de agentes em posições de chefia: seu marido, Vassíli, foi convocado para apagar o que acreditava ser um incêndio comum e enviado, como seus companheiros, sem qualquer proteção contra a radiação, sofrendo exposição a uma dose de radiação quatro vezes superior à considerada letal. A falta de cuidados se estendeu aos profissionais de saúde do primeiro hospital onde os bombeiros receberam tratamentos: "Muitos médicos, enfermeiras e, sobretudo, as auxiliares daquele hospital, depois de algum tempo, começaram a adoecer. Mais tarde morreriam. Mas na época ninguém sabia disso...” (ALEKSIÉVITCH, 2016b, loc. 141). A situação de confusão e desinformação se agrava quando aliada à presença estranha e opressiva do exército, lavando as ruas com um estranho pó branco e portando máscaras de gás. Logo a ação do poder público se torna ainda mais autoritária quando os bombeiros são deslocados à força para Moscou - operação realizada pelas costas de seus familiares, não muito distante de um sequestro:

À noite, já não me deixaram entrar no hospital. Havia um mar de gente ao redor... Fiquei em pé debaixo da janela da enfermaria; ele se aproximou e gritou alguma coisa para mim. Parecia desesperado! Alguém na multidão entendeu o que ele disse: seriam levados àquela noite para Moscou. Todas nós, esposas, nos juntamos. Decidimos: vamos com eles. "Que nos deixem ir com os nossos 
maridos! Vocês não têm direito!” Lutamos, nos atracamos com os soldados, que já haviam formado um cordão duplo e nos empurravam. Foi então que um médico surgiu e confirmou que os doentes seriam levados de avião para Moscou, e que seria preciso roupas para eles, pois as usadas na central haviam sido queimadas. Os ônibus já não circulavam, então atravessamos a cidade correndo. Quando finalmente voltamos com as sacolas, o avião já tinha partido. Fomos enganadas de propósito. Para evitar que chorássemos, que gritássemos. (ALEKSIÉVICH, 2016b, loc. 157)

Liudmila conseguiu se deslocar até Moscou com os sogros - embora não se recorde do caminho - e localizou a clínica de radiologia onde os bombeiros haviam sido alocados; para entrar e rever o marido, precisou subornar um vigia e ocultar a gravidez. Ali, abraçou-o o quanto pôde; enfermeiros e médicos procuravam afastá-la dele, mas demoraram a explicar o porquê - "Isso já não é um homem, é um reator nuclear. Vão queimar os dois" (ALEKSIÉVICH, 2016b, loc. 326) - e testemunhou seu definhamento, o descolamento de mucosas e da pele; ao final, perdeu também a filha que estava gestando. Esse monólogo, como os demais, retrata de forma pulsante o drama de Tchernóbil não em suas dimensões ambientais, mas como tragédia pessoal e psicológica.

\section{CONSIDERACÕES FINAIS}

Apesar de as estratégias textuais serem distintas, tanto em $A$ Guerra Não tem Rosto de Mulher quanto em Vozes de Tchernóbil a operação do texto de Aleksiévitch se dá numa direção contrária à dos de Hanna Krall: cenas são mais longas e descritas com maior riqueza de detalhes, promovendo o testemunho virtual dos acontecimentos (KNORR-CETINA, 1999; HARTSOCK, 2015) - a possibilidade de imergir na narrativa e imaginar-se parte dela, experienciar os acontecimentos como se fosse testemunha ocular deles, envolver-se emocionalmente. Krall, pelo contrário, promove um distanciamento entre texto e leitor: a fruição de suas reportagens se dá numa via mais analítica do que passional.

A distinção pode ficar mais clara ao se observar duas passagens em que ambas as autoras tratam de eventos semelhantes - o afogamento de uma crianças faminta e o abandono de outra em meio à rua e à perseguição pelas tropas nazistas. O trecho de Svetlana integra o capítulo "Da conversa com o Censor que diz" em A guerra não tem rosto de mulher: 
Existe um trecho na Svetlana, esse aqui no "Alguém nos entregou... Os alemães descobriram onde ficava o acampamento dos partisans. Cercaram a floresta e fecharam as passagens por todos os lados. Nos escondemos em um matagal fechado, fomos salvos pelos pântanos onde a tropa punitiva não entrava. Um lodaçal. Ele encobria muito bem tanto as pessoas quanto os equipamentos. Passamos alguns dias, semanas, com água na altura do pescoço. Havia conosco uma operadora de rádio que tivera um filho havia pouco tempo. A criança estava com fome... Pedia o peito. Mas a própria mãe estava passando fome, não tinha leite, e a criança chorava. Os soldados da tropa punitiva estavam por perto... Tinham cachorros... Se os cachorros escutassem, todos nós morreríamos. Todo o grupo, umas trinta pessoas. Entende?

\section{O comandante tomou a decisão...}

Ninguém se animava a transmitir a ordem para a mãe, mas ela mesma adivinhou. Foi baixando a criança enroladinha para a água e segurou ali por um longo tempo... A criança não gritou mais... Nenhum som... E nós não conseguíamos levantar os olhos. Nem para a mãe, nem uns para os outros..." (ALEKSIÉVITCH, 2016a, p.32)

Já o trecho de Krall - um depoimento longo, atípico em sua abordagem - faz parte da reportagem Dybuk [The Dybbuk ${ }^{2}$, selecionada do livro Dowody na istnienie [Provas de existência] para a coletânea The Woman from Hamburg and other true stories:

Yes, in a phone conversation. He was living in Iowa; I called him after I got back home. I thought he wouldn't believe me, that at the very least he'd be taken aback, but he wasn't taken aback at all. He listened calmly, and then he said, "I know what that cry is. When they threw him out of the hiding place he stood in the street and cried loudly. That was the cry-the cry of my child who was thrown out into the street."

This was the first time I had talked with my father about my brother. Father had a weak heart; I didn't want to upset him. I knew that my brother had died, like everyone else; what more was there to ask about? Now I found out that the

2 No folclore judeu, existe um espírito humano que vagueia pelo mundo em busca de um refúgio no corpo de alguém vivo devido aos pecados cometidos na vida pregressa. Esse espírito é conhecido como Dybbuk ou Dibbuk. 
boy had been hidden somewhere with his mother, my father's first wife, along with a dozen or so other Jews. I don't know where, if it was in the ghetto or on the Aryan side. Sometimes I picture a kitchen and people crowded together. They were sitting on the floor, trying not to breathe. He started crying. They tried to quiet him. How do you calm a crying child? With candy? A toy? They didn't have toys or candy. His crying grew louder and louder, and the people crowded together on the floor were thinking the same thought. Someone whispered: "We're all going to die because of one little kid." Or maybe it wasn't a kitchen. Maybe it was a cellar, or a bunker. My father wasn't with them; only she was, Abram's mother. She stayed with the others. She survived. She settled in Israel, maybe she's still living there, I didn't ask, I don't know....

My father died. (KRALL, 2005, loc.1521)

Para além disso, Krall segue também na contramão de um dos valores básicos da narrativa do jornalismo literário, a que mais a ancora à prática da reportagem: a precisão de dados; porém, como afirmamos, utiliza a imprecisão como trunfo ao promover uma interação mais ativa entre texto e leitor: as informações continuam ali, mas não de forma evidente - por vezes é preciso garimpá-las, por vezes intui-las. O mundo que reconstrói textualmente é um complexo mosaico em cacos no qual cabe ao processo de leitura reunir os pedaços e lhes conferir sentido.

A omissão de informações - entre indivíduos, entre pessoas e instituições - desponta como tema comum às duas repórteres: personagens femininas, principalmente, aparecem atiradas a um mundo que não se esforça por integrá-las, por lhes inteirar dos acontecimentos, que muitas vezes lhes omite o essencial; elas, por sua vez, precisam silenciar e omitir informações para sobreviver. A partir dessa representação a história das mulheres eslavas parece ser, por um lado, a narrativa de seu apagamento pelas sociedades machistas - o apagamento de sua experiência, de suas conquistas e lutas tanto quanto de sua opressão - e, por um lado, a de seu silenciamento frente às dinâmicas sociais em que já se antecipa que seriam apagadas e caladas.

\section{REFERÊNCIAS}

ALEKSIÉVITCH, Svetlana. A Guerra Não Tem Rosto de Mulher. São Paulo: Companhia das Letras, 2016 a.

ALEKSIÉVITCH, Svetlana. Vozes de Tchernóbil: a história oral do desastre nuclear. São Paulo: Companhia das Letras, 2016b. (ebook) 
BAKHTIN, Mikhail. O Freudismo. 2. ed. São Paulo: Perspectiva, 2012.

BAKHTIN, Mikhail. Os gêneros do discurso. São Paulo: Editora 34, 2016.

CHKLOVSKI, Viktor. A arte como procedimento. In: TODOROV, Tzvetan. Teoria da literatura Textos dos formalistas russos. São Paulo: Editora Unesp, 2013.

CORREIO BRAZILIENSE. Quem é Svetlana Alexijevich? Conheça a vencedora do Nobel da Literatura. Disponível em: https://www.correiobraziliense.com.br/app/noticia/diversao-e-arte/2015/10/08/interna_diversao_arte,501775/conheca-a-bielo-russa-que-venceu-o-premio-nobel-de-literatura.shtml. Publicado em: 8 out. 2015. Acesso em: 29 mai. 2018.

CULTURE.PL. Hanna Krall. Disponível em: https://culture.pl/en/artist/hanna-krall Acesso em: 27 mai. 2018.

HARTSOCK, John C. Literary journalism and the aesthetics of experience. Amherst: University of Massachussetts Press, 2015.

ISER, Wolfgang. Der Akt des Lesens: theorie asthetischer Wirkung. München: Wilhelm Fink, 1976.

KNORR-CETINA, Karin. A comunicação na ciência. In: GIL, Fernando (Org.). A ciência tal qual se faz. Lisboa: Edições João Sá da Costa, 1999, p. 375-393.

KRALL, Hanna. The Woman from Hamburg and other true stories. New York: Other Press, 2005. (ebook)

LIMA, Edvaldo Pereira; MARTINEZ, Monica. Eliane Brum: new star in Brazil's Literary Journalism firmament. In: KEEBLE, Richard Lance; TULLOCH, John. (Orgs.). Global Literary Journalism v.2 exploring the journalistic imagination. New York: Peter Lang, 2014, p. 171-181.

OGIOLD, Krzysztof. Mózg to jest przereklamowany organ. Nowa Trybuna Opolska, 2 nov.2001. Disponível em: http://www.nto.pl/artykuly-archiwalne/art/3948257,mozg-to-jest-przereklamowany-organ,id,t. html Acesso em: 27 maio 2018.

PASSOS, Mateus Yuri. De fontes a personagens: definidores do real no jornalismo literário. In: SOSTER, Demétrio de Azeredo; PICCININ, Fabiana (Orgs.). Narrativas midiáticas contemporâneas: perspectivas epistemológicas. Santa Cruz do Sul: Catarse, 2017, p. 86-97.

RICHARDS, I. A. Practical criticism. London: Routledge, 2017.

SIMS, Norman. True Stories: a century of literary journalism. Evanston: Northwestern University Press, 2007.

WOLFE, Tom. Radical chique e o Novo Jornalismo. São Paulo: Companhia das Letras, 2005. 